\title{
Low-temperature heat utilization with vapor pressure-driven osmosis: Impact of membrane properties on mass and heat transfer
}

\author{
Xi Chen ${ }^{\mathrm{a}}$, Chanhee Boo ${ }^{\mathrm{a}}$, Ngai Yin Yip ${ }^{\mathrm{a}, \mathrm{b}, *}$ \\ ${ }^{a}$ Department of Earth and Environmental Engineering, Columbia University, New York, NY, 10027-6623, United States \\ ${ }^{\mathrm{b}}$ Columbia Water Center, Columbia University, New York, NY, 10027-6623, United States
}

\section{A R T I C L E I N F O}

\section{Keywords:}

Vapor pressure-driven osmosis

Low-temperature heat

Hydrophobic membranes

Mass transfer

Heat transfer

\begin{abstract}
A B S T R A C T
The emerging vapor pressure-driven osmosis (VPDO) membrane technology enables direct conversion of abundant low-temperature $\left(<100^{\circ} \mathrm{C}\right)$ heat resources to useful work. In this study, a theoretical model is established to understand mass and heat transfer of VPDO, and two hydrophobic nanoporous membranes, polypropylene (PP) and polytetrafluoroethylene (PTFE), of different chemistry and structural properties were evaluated. Although the PP membrane has a less effective transport pathway, the considerably larger pore size yields a much higher Knudsen diffusivity that results in consistently higher vapor fluxes across different temperature-pressure conditions. This finding provides strong evidence that mass transfer in VPDO is dominated by Knudsen diffusion. Additionally, we find that operation at higher pressurizations caused vapor flux decline that is attributed to the membrane morphological deformation. However, the PP membrane is less sensitive to the effects of compaction, underlining the importance of membrane mechanical robustness for VPDO. Lastly, the study shows that evaporative heat transfer is significantly greater than conductive losses and the PP membrane, with higher water fluxes, has better evaporation thermal efficiencies. This study provides fundamental understanding on the impacts of membrane properties on mass and heat transfer in VPDO, and highlights the centrality of vapor permeability and mechanical robustness in developing high-performance membranes.
\end{abstract}

\section{Introduction}

Low-temperature heat resources below $100{ }^{\circ} \mathrm{C}$ exist in vast amounts and are widely accessible. As much as $50 \%$ of industrial energy input is reported to be lost as waste heat [1], of which $42 \%$ is estimated as heat below $100^{\circ} \mathrm{C}$ [2]. In the United States alone, around 10.6 EJ of waste heat is generated each year [3]; in comparison, the annual national energy consumption is $105.6 \mathrm{EJ}$ in 2018 [4]. Geothermal energy housed in Earth's crust is another abundant source. Heat up to $100^{\circ} \mathrm{C}$ can be obtained from shallow wells at less than $3.5 \mathrm{~km}$ beneath the ground nationwide in the United States [5,6], with the total U.S. geothermal energy estimated to be $\approx 14 \times 10^{6} \mathrm{EJ}$ [6]. So far, only a tiny proportion of these readily accessible low-temperature heat is utilized. As such, low-grade heat offers promising opportunities for sustainable energy production.

Due to the relatively poor heat quality, currently there is a lack of technologies that can efficiently utilize the low-temperature thermal energy. Solid-state thermoelectric devices can use low-temperature heat, but oftentimes require expensive exotic materials and are, hence, not cost-effective $[7,8]$. Various thermo-electrochemical systems have been developed for power generation with low-temperature heat utilizing metal complexation reactions [9-11], or temperature-dependent electrochemical redox potentials [12-14]. However, these processes typically suffer from poor energy efficiencies.

Recently, a vapor pressure-driven osmosis (VPDO) membrane technology, also termed "thermo-osmotic energy conversion (TOEC)" [15-17] or "pressure-retarded membrane distillation (PRMD)" [18], has been proposed to extract useful work from low-grade heat. Working principle of VPDO is based on vapor transfer across a hydrophobic nanoporous channel as depicted in Fig. 1. The membrane separating the hot and cold streams is hydrophobic and, hence, the nanoscale pores are not wetted. The temperature difference between the streams sets up a vapor pressure gradient, thus driving vapor flux across the membrane. Subsequent vapor condensation at the cold side increases the cold stream volume, resulting in buildup of transmembrane hydraulic pressure difference $(\Delta P)$. This hydraulic pressure can be converted to useful work by depressurizing through a hydroturbine, i.e., thermal energy $\rightarrow$ mechanical energy $\rightarrow$ electrical energy. The power generation process can be described by $W=\int \Delta P \mathrm{~d} V$, where $W$ is the useful work and $\mathrm{d} V$ is the increase in cold stream volume. The product of

\footnotetext{
* Corresponding author. Department of Earth and Environmental Engineering, Columbia University, New York, NY, 10027-6623, United States.

E-mail address: n.y.yip@columbia.edu (N.Y. Yip).
} 


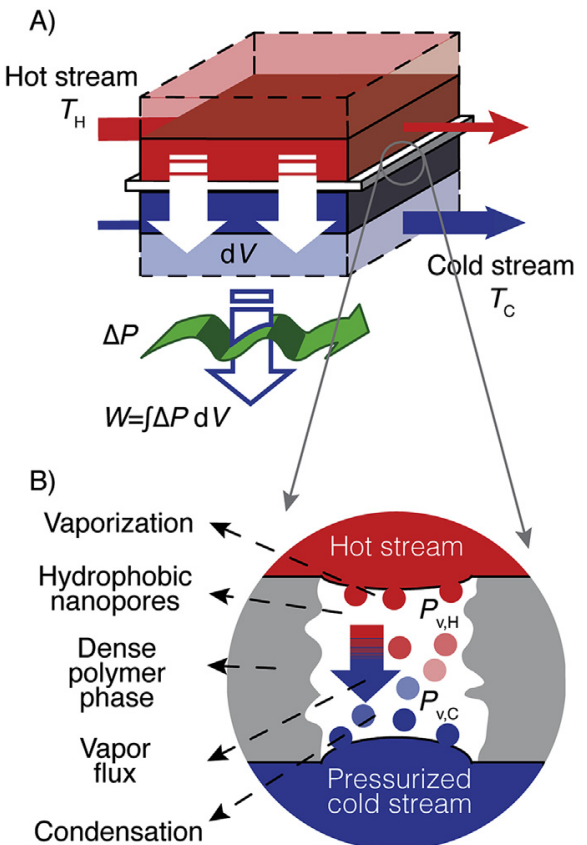

Fig. 1. Schematic diagram of VPDO membrane technology. A) Working principles of VPDO energy production, where two streams are separated by a hydrophobic, i.e., non-wetting, nanoporous membrane. The difference between hot- and cold-stream temperatures, $T_{\mathrm{H}}$, and $T_{\mathrm{C}}$, drives vapor flux (white arrows) across the hydrophobic membrane. The permeated vapor condenses and increases the cold stream volume, $\mathrm{d} V$, setting up a transmembrane hydraulic pressure difference, $\Delta P$ (represented by the green wavy arrow). Therefore, useful work produced is $W=\int \Delta P \mathrm{~d} V$. B) Transport across the membrane nanopores. The vapor flux driven by the difference between the hot- and coldstream partial pressures, $P_{\mathrm{v}, \mathrm{H}}$ and $P_{\mathrm{V}, \mathrm{C}}$, respectively, transport through the hydrophobic nanopores of the membrane matrix, and condenses at the pressurized cold stream. (For interpretation of the references to color in this figure legend, the reader is referred to the Web version of this article.)

vapor flux and hydraulic pressure yields the power density (or, equivalently, $W$ normalized by the effective membrane area). Hence, vapor flux and $\Delta P$ are important performance parameters for VPDO.

To advance the emerging VPDO membrane technology towards actual utilization of low-grade heat for energy production, enhanced fundamental understand of the process is first needed. While theoretical analyses have shed light on the performance-limiting effects of the VPDO process and suggested desirable membrane properties $[16,18]$, experimental validations of these analytical results are lacking. To date, there are no commercial membranes specifically designed for VPDO and, so far, experimental tests on only one commercial ultrafiltration membrane and one lab-fabricated asymmetric membrane have been reported $[15,19,20]$. Understanding the role of the membrane properties in the performance of the VPDO technology is vital for improving process efficiency and for the development of high-performance membranes.

The objective of this study is to investigate the effects of membrane chemistry and structure on the performance of VPDO. Vapor flux and evaporation thermal efficiency of two hydrophobic nanoporous membranes with different chemical compositions and structural properties were evaluated under a range of transmembrane temperature gradients and applied hydraulic pressures. A model describing mass and heat transport is presented and employed to explain the experimental membrane performance. Lastly, implications of the findings for converting low-grade heat to useful work by VPDO are discussed.

\section{Theory}

\subsection{Mass transfer in VPDO}

Mass transfer through the hydrophobic nanoporous membrane can be described using a generalized form of the Maxwell-Stefan equation combined with the dusty-gas model [21-23]. With reasonable simplifications, vapor mass flux across the membrane in VPDO, $J_{\mathrm{v}}$, can be derived $[24,25]$ :

$J_{\mathrm{v}} \approx\left[\frac{\varepsilon M_{\mathrm{w}}}{\tau \delta R_{\mathrm{g}} T}\left(\frac{1}{D_{\mathrm{wa}}}+\frac{1}{D_{\mathrm{K}}}\right)^{-1}\right]\left(P_{\mathrm{v}, \mathrm{H}}-P_{\mathrm{v}, \mathrm{C}}\right)=B_{\mathrm{v}}\left(P_{\mathrm{v}, \mathrm{H}}-P_{\mathrm{v}, \mathrm{C}}\right)$

where the difference between vapor pressures of the hot and cold streams, $P_{\mathrm{v}, \mathrm{H}}$ and $P_{\mathrm{v}, \mathrm{C}}$ respectively, signifies the driving force for vapor flux. $M_{\mathrm{w}}$ is the molar mass of water, $R_{\mathrm{g}}$ is the gas constant, $T$ is the mean temperature in the membrane matrix, and $D_{\mathrm{wa}}$ and $D_{\mathrm{K}}$ are coefficients of molecular diffusion and Knudsen diffusion, respectively. Parameters that characterize the membrane structure are porosity, $\varepsilon$, thickness, $\delta$, and pore tortuosity, $\tau$. Aggregating these membrane properties and physical constants together yields the membrane vapor permeability coefficient, $B_{\mathrm{v}}$, which describes an intrinsic vapor transport property of the hydrophobic nanoporous membrane.

As indicated by Eq. (1), mass transport in the VPDO process is governed by the Knudsen diffusion and molecular diffusion mechanisms. Knudsen diffusion coefficient, $D_{\mathrm{K}}$, describes resistance to mass (vapor) transport based on collisions between vapor molecules and the pore wall with an effective pore radius of $r_{\text {eff }}$ and is given by Eq. (2) [26-28].

$D_{\mathrm{K}}=\frac{4 r_{\mathrm{eff}}}{3} \sqrt{\frac{2 R_{\mathrm{g}} T}{\pi M_{\mathrm{w}}}}$

The interaction between water vapor and air molecules, which describes the molecular diffusion mechanism, is characterized by $D_{\text {wa. }}$. An empirical correlation proposed by Fuller, Schettler, and Giddings $[29,30]$ is:

$D_{\mathrm{wa}}=\frac{T^{1.75} \sqrt{\frac{M_{\mathrm{w}}+M_{\mathrm{a}}}{M_{\mathrm{w}} M_{\mathrm{a}}}}}{P_{\mathrm{a}}\left(V_{\mathrm{w}}^{1 / 3}+V_{\mathrm{a}}^{1 / 3}\right)^{2}}$

where $M_{\mathrm{a}}$ is the molar mass of air, $V_{\mathrm{w}}$ and $V_{\mathrm{a}}$ are the molar volumes of water vapor and air, respectively, and $P_{\mathrm{a}}$ indicates the pressure of air within the pore. Note that $B_{\mathrm{v}}$ varies within $1 \%$ between temperatures of $20-80^{\circ} \mathrm{C}$ that are relevant in VPDO and, thus, can be considered temperature-independent in this study.

As shown in Eqs. (1)-(3), membrane porosity, thickness, and tortuosity determine an effective pathway for vapor transport ( $\delta \tau / \varepsilon$ in Eq. (1)), whereas the ratio of effective membrane pore size, $r_{\text {eff }}$, to the molecular mean free path, affects the relative contributions of Knudsen diffusion and molecular diffusion to mass transfer resistance (Eqs. (2) and (3)). For instance, vapor transport through pores having small effective radii, $r_{\text {eff }}$, is dominated by Knudsen diffusion. Thus, effective mass transfer is expected for membranes with high porosity, low tortuosity, and small thickness, whereas large pore sizes are anticipated to be also desirable for high vapor flux.

\subsection{Heat transfer in VPDO}

Heat transfer in VPDO is governed by both convection and heat conduction. Total heat flux through the hydrophobic nanoporous membrane, $\dot{Q}$, can be expressed as $[23,26,31,32]$.

$\dot{Q}=J_{\mathrm{v}} \Delta H_{\mathrm{v}}+\frac{k_{\mathrm{m}}}{\delta}\left(T_{\mathrm{H}, \mathrm{m}}-T_{\mathrm{C}, \mathrm{m}}\right)$

where $\Delta H_{\mathrm{v}}$ is the enthalpy of water vaporization, $k_{\mathrm{m}}$ is the membrane thermal conductivity, and $T_{\mathrm{H}, \mathrm{m}}$ and $T_{\mathrm{C}, \mathrm{m}}$ are liquid-pore interfacial 
temperatures at the hot- and cold-stream sides, respectively. The first term in Eq. (4), $J_{\mathrm{v}} \Delta H_{\mathrm{v}}$, denotes evaporative heat flux associated with the latent heat of water vaporization, and the second term, $k_{\mathrm{m}}\left(T_{\mathrm{H}, \mathrm{m}}-T_{\mathrm{C}, \mathrm{m}}\right) / \delta$, presents conductive heat transfer across the membrane matrix. We note that $\Delta H_{\mathrm{v}}$ of the condensation process varies $<$ $1 \%$ from that of the vaporization process. For simplification of analysis, $\Delta H_{\mathrm{v}}$ is assumed to be constant in this study, i.e., the process can be considered as adiabatic.

Useful work is produced in VPDO by driving vapor flux across a hydrophobic nanoporous membrane from a hot stream to a pressurized cold stream. The evaporation thermal efficiency, $\alpha_{\text {evp }}$, is defined as the ratio of heat utilized for water vaporization to the total heat flux across the membrane, Eq. (5). A higher $\alpha_{\text {evp }}$ indicates a more efficient conversion of thermal energy to useful work [16], with lesser conductive heat loss.

$\alpha_{\text {evp }}=\frac{J_{\mathrm{v}} \Delta H_{\mathrm{v}}}{J_{\mathrm{v}} \Delta H_{\mathrm{v}}+\frac{k_{\mathrm{m}}}{\delta}\left(T_{\mathrm{H}, \mathrm{m}}-T_{\mathrm{C}, \mathrm{m}}\right)}$

We note that $\alpha_{\text {evp }}$ is strongly affected by membrane properties since $J_{\mathrm{v}}$ is a function of membrane pore size, porosity, and tortuosity (Eq. (1)), and $k_{\mathrm{m}}$ is dependent on chemistry and porosity of the membrane. As shown earlier in Eq. (1), vapor flux, $J_{\mathrm{v}}$, is inversely proportional to the membrane thickness, $\delta$. Hence, the influence of the membrane thickness on $\alpha_{\text {evp }}$ (i.e., term $1 / \delta$ ) cancels out in Eq. (5), indicating that the evaporation thermal efficiency is independent of membrane thickness. Note that $\alpha_{\text {evp }}$ is not directly related to power density.

\section{Materials and methods}

\subsection{Hydrophobic nanoporous membranes}

Two commercial hydrophobic nanoporous membranes having different chemical and structural properties were investigated in this study. Polypropylene (PP) membrane with nominal pore size of $100 \mathrm{~nm}$ was acquired from Membrana $\mathrm{GmbH}$ (Wuppertal, Germany). Polytetrafluoroethylene (PTFE) membrane was obtained from Pall Corporation (Westborough, MA) and comprises a thin hydrophobic PTFE layer with nominal 20-nm pores supported by a polyester (PET) substrate.

\subsection{Membrane characterization}

\subsubsection{Characterization of structural properties}

Surface and cross-sectional morphologies of the PP and PTFE membranes were investigated using scanning electron microscope (SEM, Zeiss Sigma VP, Oberkochen, Germany). To obtain cross-sectional images, dry membranes were frozen in liquid nitrogen and then fractured aided by a razor blade. All samples were sputter-coated with a 20-nm gold layer (108 auto sputter, Cressington, UK) before imaging. Membrane surface roughness was measured by atomic force microscopy (AFM, Bruker Dimension FastScan AFM, Bruker, Germany) in tapping mode with a scan area of $2.0 \times 2.0 \mu \mathrm{m}$. For each membrane coupon, three different locations were scanned and the data were processed using Gwyddion software to obtain the average surface roughness. The membrane thickness was measured with a digital micrometer and also determined from the cross-sectional SEM micrographs using ImageJ software.

\subsubsection{Contact angle measurements and surface free energy calculations}

Water contact angles were measured with a goniometer (ramé-hart Model 260, Succasunna, NJ) using the static sessile drop method [33], and analyzed by a post-processing software (DROPimage Advanced software). Surface free energies of both the PP and PTFE membranes were calculated using the revised Young's equation [34]: $\cos \theta_{\text {in }}=-1+2 \sqrt{\frac{\gamma_{\mathrm{s}}}{\gamma_{1}}} \exp \left[-\beta\left(\gamma_{1}-\gamma_{\mathrm{s}}\right)^{2}\right]$

where $\theta_{\text {in }}$ indicates the intrinsic water contact angle on a perfectly smooth surface, $\gamma_{1}$ is the surface tension of the liquid, i.e., deionized (DI) water, $\gamma_{\mathrm{s}}$ is the surface free energy of the membrane, and $\beta$ is an empirical constant, $124.7 \mathrm{~m}^{4} / \mathrm{J}^{2}$ [34]. $\theta_{\text {in }}$ is calculated from the apparent contact angle measured on the actual rough membrane surface, $\theta_{\mathrm{app}}$, using the Wenzel model, $\cos \theta_{\text {app }}=r_{\text {rg }} \cos \theta_{\text {in }}$, with $r_{\text {rg }}$ being the surface roughness factor, defined as the ratio of actual surface area to the projected area. The surface roughness factor was obtained from AFM analysis $[33,35]$.

\subsubsection{Liquid entry pressure test}

Liquid entry pressures, LEPs [36], were determined using a custombuilt membrane test cell (detailed later in section 3.3.1). DI water is circulated in the bottom channel of the membrane cell and different hydraulic pressures were applied against the hydrophobic layer of the membranes using a gear pump and a back-pressure regulator. The top cell channel was open to the atmosphere. The bottom channel pressure was increased from 69 to $2070 \mathrm{kPa}(10-300 \mathrm{psi})$ in increments of $69 \mathrm{kPa}(10 \mathrm{psi})$, with each pressure maintained for $15 \mathrm{~min}$. The pressure at which water leakage is first observed was reported as the membrane LEP. Maximum effective pore size, $d_{\mathrm{p} \text {, max }}$, can be calculated from the measured LEP value using the Laplace-Young equation [33]:

$\mathrm{LEP}=\Delta P_{1, \mathrm{C}}=-\frac{4 \gamma_{1} \cos \theta_{\mathrm{app}}}{d_{\mathrm{p}, \max }}$

where $\Delta P_{1, \mathrm{C}}$ is the pressure difference at the liquid-pore interface.

\subsubsection{Porosity and pore size distribution measurement}

Membrane porosity was determined by a gravimetric method [37]. Membrane samples were first completely wetted using isopropanol and then immersed in several DI water baths to exchange the pore-filled isopropanol with DI water. The dry and water-wetted samples were weighed using a microbalance and the sample porosity, $\varepsilon$, was calculated by

$\varepsilon=\frac{\left(m_{\text {wet }}-m_{\text {dry }}\right) \rho_{\mathrm{p}}}{m_{\text {dry }} \rho_{\mathrm{w}}}$

where $m_{\text {wet }}$ and $m_{\mathrm{dry}}$ are the weights of the wetted and dry membranes, respectively, and $\rho_{\mathrm{p}}$ and $\rho_{\mathrm{w}}$ are the densities of membrane polymer and water, respectively. Because the PTFE layer peeled off from the PET support crumbles up, porosity of the PTFE membrane was determined from the properties of the integral membrane and PET support layer:

$\varepsilon^{\mathrm{PTFE}}=\frac{\left(m_{\mathrm{wet}}^{\mathrm{int}}-m_{\mathrm{wet}}^{\mathrm{PET}}-m_{\mathrm{dry}}^{\mathrm{PTF}}\right) \rho_{\mathrm{p}}}{\left(m_{\mathrm{wet}}^{\text {int }}-m_{\mathrm{wet}}^{\mathrm{PET}}-m_{\mathrm{dry}}^{\mathrm{PTFE}}\right) \rho_{\mathrm{p}}+m_{\mathrm{dry}}^{\mathrm{PTFE}} \rho_{\mathrm{w}}}$

where superscripts "int", "PTFE", and "PET" denote properties of the integral membrane, PTFE layer, and PET support, respectively.

Membrane pore size distributions were characterized by a custombuilt capillary porometer setup using the wet/dry flow method. Detailed methodology is described elsewhere [38,39]. Briefly, flowrates of nitrogen gas across the dry and fully-wetted membranes were measured at the same gas pressure increments. The pore size at a certain gas pressure can be calculated using the Laplace-Young equation. The fraction of pores with the corresponding size is determined from the difference in gas flowrates measured from wet and dry permeation tests $[38,39]$.

\subsection{Experimental set-up of flux tests}

\subsubsection{Bench-scale system}

The bench-scale experimental VPDO setup is illustrated in Fig. 2. Gear pumps were used to circulate the hot and cold streams as 


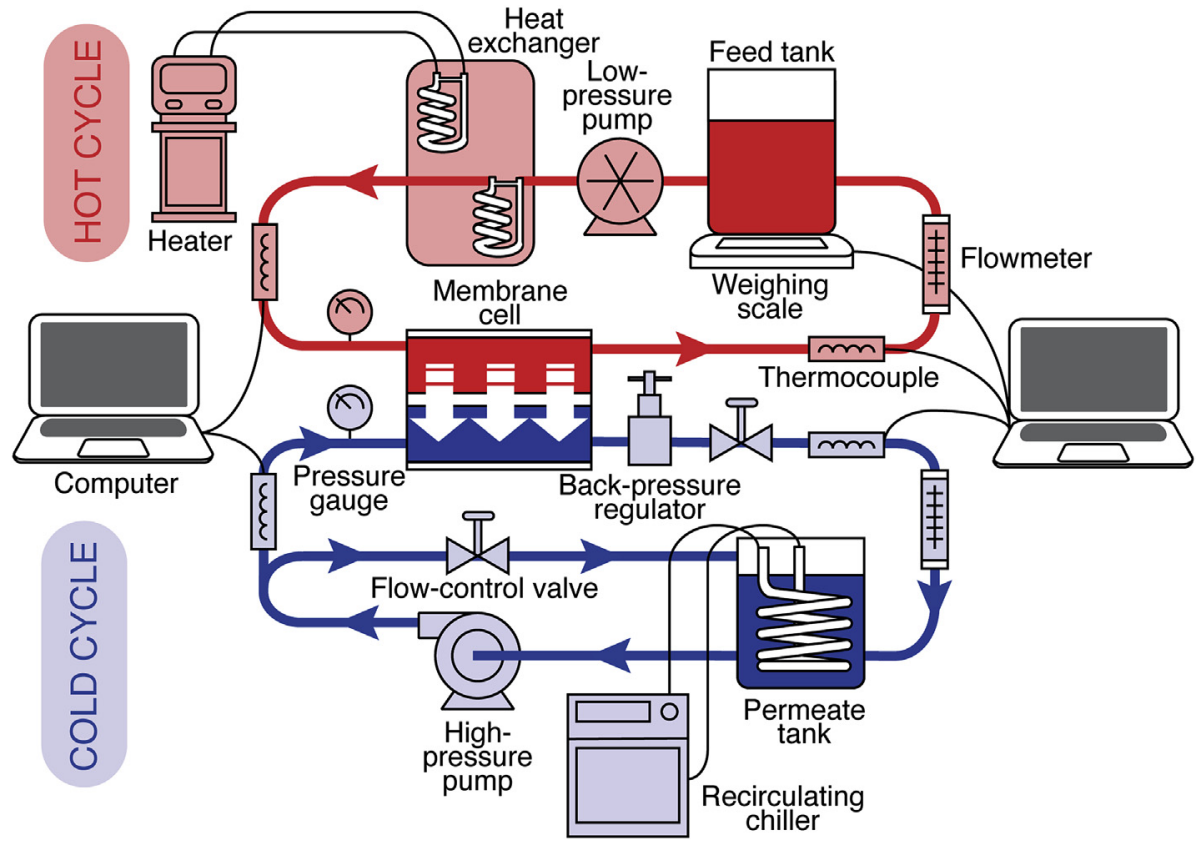

Fig. 2. Schematic diagram of the bench-scale experimental setup for the VPDO membrane flux tests. Red and blue color represents the hot and cold steam, respectively. Vapor flux is recorded by the rate of weight change of the hot feed tank. (For interpretation of the references to color in this figure legend, the reader is referred to the Web version of this article.) represented in red and blue, respectively. The hydraulic pressure and flowrate of the cold stream were adjusted by a back-pressure regulator and a flow-control needle valve. Hot- and cold-stream temperatures were controlled by a circulating bath and a refrigerated recirculating chiller, respectively (PolyScience, Niles, IL). A custom-built crossflow membrane cell was used for VPDO performance test. The length and width of the channel on both sides are 107 and $36 \mathrm{~mm}$, respectively, whereas channel depths of the hot and cold sides are 0.5 and $3.0 \mathrm{~mm}$, respectively. A customized two-layer woven tricot spacer was applied in the hot-stream channel to support the membrane geometry and to enhance hydrodynamics. Effective membrane area of $19.0 \mathrm{~cm}^{2}$ $(2.5 \times 7.6 \mathrm{~cm})$ was exposed to the hot and cold streams. Entry and exit temperatures of the membrane cell for both the hot and cold streams were measured by custom-made K-type thermocouples (Omega Engineering, Norwalk, CT) and recorded with LabJack U6 data logger (Lakewood, CO). The weight of a hot feed tank was continuously recorded by a digital scale and logged using WinWedge software (TAL Technologies, Philadelphia, PA).

\subsubsection{Experimental protocol}

For both hot and cold streams, DI water was used as the working fluid, operated in a co-current mode at a flowrate of $0.4 \mathrm{~L} / \mathrm{min}$. Vapor flux across the membrane was driven by the temperature gradient of 20 , 35 , or $50^{\circ} \mathrm{C}$, achieved by varying the bulk-phase temperature in the hot stream, $T_{\mathrm{H}}$, while maintaining the cold stream bulk-phase temperature, $T_{\mathrm{C}}$, at $293 \mathrm{~K}\left(20^{\circ} \mathrm{C}\right)$. At each temperature gradient, three different hydraulic pressures, $P_{\mathrm{h}}$, were applied at the cold stream to produce the transmembrane pressure difference, $\Delta P$, for power generation. Because the hot stream is effectively at ambient pressure, $\Delta P \approx P_{\mathrm{h}}-0=P_{\mathrm{h}}$. Additionally, the hydrophobic nanoporous membranes need to withstand $P_{\mathrm{h}}$ without wetting during VPDO operation. To evaluate the performance of the PP and PTFE membranes under identical VPDO operating conditions, the hydraulic pressures were chosen based on the lower LEP of the two membranes. In this study, $P_{\mathrm{h}}$ of 69,207 , and $414 \mathrm{kPa}(10,30$, and $60 \mathrm{psi})$ were applied (LEP results discussed in section 4.1). For each temperature-pressure condition pair, VPDO experiments were carried out in triplicates using fresh membrane coupons. Steady-state vapor flux was determined from the rate of weight change of the hot-stream tank over $15 \mathrm{~min}$, after the vapor flux had stabilized. Additional weight loss attributed to water evaporation from the hot-stream tank was corrected by baseline tests using nonpermeable aluminum foil coupons (i.e., no vapor flux from the hot to feed stream side), and was monitored to be $<8 \%$ of the total vapor flux across the membrane in all experimental runs.

\section{Results and discussion}

\subsection{Membrane characteristics}

Top, bottom, and cross-sectional SEM micrographs of the PP and PTFE membranes are shown in Fig. 3. The top surface of the PP membrane features a globular structure, which is typical of membranes prepared via phase separation (Fig. 3-A1) [40]. A similar form of polymer aggregation with a globular structure was observed for the bottom side of the PP membrane (Fig. 3-A2) [41]. The PTFE membrane showed a highly fibrillated structure on the top surface (Fig. 3-B1), whereas a non-woven polyester substrate was observed at the bottom of the membrane (Fig. 3-B2). Average surface roughness of the PP and PTFE membranes, $R_{\text {avg }}$, are 101.7 and $124.4 \mathrm{~nm}$, respectively, as characterized by AFM (Table 1) [42]. The surface roughness factors, $r_{\mathrm{rg}}$, of the PP and PTFE membranes were calculated using the actual and projected membrane surface area obtained from the AFM imaging to be 2.44 and 1.89 , respectively (Table 1 ).

Apparent water contact angles of the PP and PTFE membranes are $129.1^{\circ}$ and $137.4^{\circ}$, and the surface free energies of these membranes, $\gamma_{\mathrm{s}}$, were calculated to be $20.04 \times 10^{-3} \mathrm{~J} / \mathrm{m}^{2}$ and $15.39 \times 10^{-3} \mathrm{~J} / \mathrm{m}^{2}$, respectively, using Eq. (6) (Table 1). The surface free energies are in good agreement with reported literature values [43]. LEP of the PTFE membrane $(1790 \mathrm{kPa})$ is higher than the PP membrane $(510 \mathrm{kPa})$. The higher LEP of the PTFE membrane is attributed to the smaller pore size, lower surface energy, and rougher surface texture that provide better resistance to pore wetting (Eq. (7)) [33,44]. Thickness of the PP and PTFE membranes obtained using a micrometer, $92.3 \mu \mathrm{m}$ and $55.3 \mu \mathrm{m}$, are comparable to those determined from their cross-sectional SEM micrographs (Fig. 3-A3 and 3-B3), $99.7 \mu \mathrm{m}$ and $42.9 \mu \mathrm{m}$, respectively. Subsequent analysis utilized the thickness values obtained by digital micrometer.

Porosity of the PTFE membrane (83.6\%) is markedly higher compared to that of the PP membrane (69.9\%). Pore size distributions of the two membranes can be inferred from Fig. 4, showing the occurrence of different pore sizes $\left(d_{\mathrm{p}}\right)$ based on the wet/dry flow method $[39,45]$. The largest pores are $\approx 420$ and $350 \mathrm{~nm}$ for the PP and PTFE membranes, 


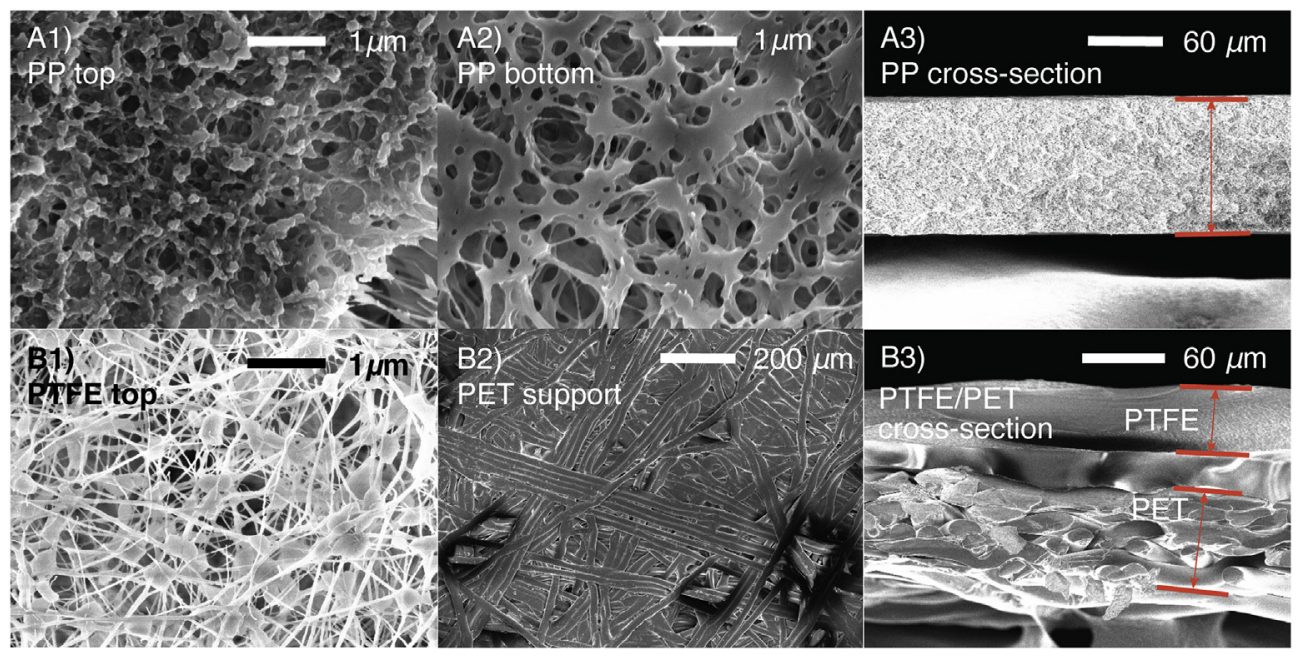

Fig. 3. SEM micrographs of the membranes. A1) and A2) show planar views of the top and bottom sides, respectively, and A3) is the cross-sectional view of the PP membrane. B1) Top planar view of the PTFE active layer, B2) bottom planar view of the PET support layer, and B3) cross-section of the composite PTFE/PET membrane. Separate layers are indicated by the red arrows. (For interpretation of the references to color in this figure legend, the reader is referred to the Web version of this article.)

Table 1

Properties of PP and PTFE membranes.

\begin{tabular}{lll}
\hline Membrane characteristics & PP & PTFE \\
\hline Surface roughness, $R_{\text {avg }}(\mathrm{nm})$ & $101.7 \pm 28.3$ & $124.4 \pm 13.4$ \\
Roughness factor, $r_{\mathrm{rg}}$ & $2.44 \pm 0.61$ & $1.89 \pm 0.03$ \\
Water contact angle, $\theta_{\text {app }}\left({ }^{\circ}\right)$ & $129.1 \pm 3.1$ & $137.4 \pm 2.2$ \\
Surface free energy, $\gamma_{\mathrm{s}}\left(\times 10^{-3} \mathrm{~J} / \mathrm{m}^{2}\right)$ & 20.04 & 15.39 \\
Membrane thickness, $\delta_{\mathrm{m}}(\mu \mathrm{m})$ & $92.3 \pm 3.31$ & $55.3 \pm 15.7$ \\
Support thickness, $\delta_{\mathrm{spt}}(\mu \mathrm{m})$ & 0 & 41.3 \\
LEP $(\mathrm{kPa})$ & 510 & 1790 \\
${ }^{\mathrm{a}}$ Nominal pore size, $d_{\mathrm{p}, \mathrm{eff}}(\mathrm{nm})$ & 100 & 20 \\
Maximum surface pore size, $d_{\mathrm{p}, \max }(\mathrm{nm})$ & 360.0 & 118.5 \\
Membrane porosity, $\varepsilon(\%)$ & $69.9 \pm 0.3$ & $83.6 \pm 0.2$ \\
\hline
\end{tabular}

a Manufactures' specifications.

respectively. It is worthwhile to note the largest pores measured using capillary porometry directly determine the membrane LEP. Because of the bilayer composition, the pore size distribution of Fig. 4B is effectively governed by the top PTFE layer, whereas the PET support layer is the main contributor to the bulk membrane porosity. The median pore size of the PP membrane is comparable to the manufacturers' nominal pore size value of $100 \mathrm{~nm}$. Due to measurement limitation of the wet/ dry flow method, smaller pore sizes down to manufacturers' specifications of $20 \mathrm{~nm}$ are not characterized.

\subsection{Impact of membrane chemistry and structure on mass transfer}

Vapor fluxes of the PP and PTFE membranes evaluated under different transmembrane temperature gradients and hydraulic pressures, $P_{\mathrm{h}}$, are presented in Fig. 5. An exponential increase in vapor flux, $J_{\mathrm{v}}$, with increasing temperature difference across the membrane was observed for both membranes and for all $P_{\mathrm{h}}$. Vapor pressure of the hot stream, $P_{\mathrm{v}, \mathrm{H}}$, in excess of the cold side vapor pressure, $P_{\mathrm{v}, \mathrm{C}}$, provides the driving force for vapor flux. The exponential vapor flux-temperature relationship can be explained by the Clausius-Clapeyron equation:

$P_{\mathrm{v}, \mathrm{H}}=P_{\mathrm{v}, \mathrm{C}}^{*} \exp \left[\frac{\Delta H_{\mathrm{v}}}{R_{\mathrm{g}}}\left(\frac{1}{T_{\mathrm{C}}^{*}}-\frac{1}{T_{\mathrm{H}, \mathrm{m}}}\right)\right]$

where $P_{\mathrm{v}, \mathrm{C}}^{*}$ and $T_{\mathrm{C}}^{*}$ are the vapor pressure and temperature at reference state (273 $\mathrm{K}$ at atmospheric pressure), respectively, and $T_{\mathrm{H}, \mathrm{m}}$ is temperature at the liquid-air interface. As $P_{\mathrm{v}, \mathrm{C}}$ is effectively maintained constant, Eq. (10) represents the effective driving force for vapor flux, which increases exponentially with $T_{\mathrm{H}, \mathrm{m}}$. This theoretical prediction corresponds well with the observed increase in vapor fluxes of the PP and PTFE membranes with increasing hot stream temperature as shown in Fig. 5.

The PP membrane achieved higher $J_{\mathrm{v}}$ than the PTFE membrane (Fig. 5A and B, respectively) under the same pressurizations as expected from its higher vapor permeability, $B_{\mathrm{v}} \quad\left(4.31 \times 10^{-7}\right.$ and $3.37 \times 10^{-7} \mathrm{~s} / \mathrm{m}$ for PP and PTFE membranes, respectively), calculated
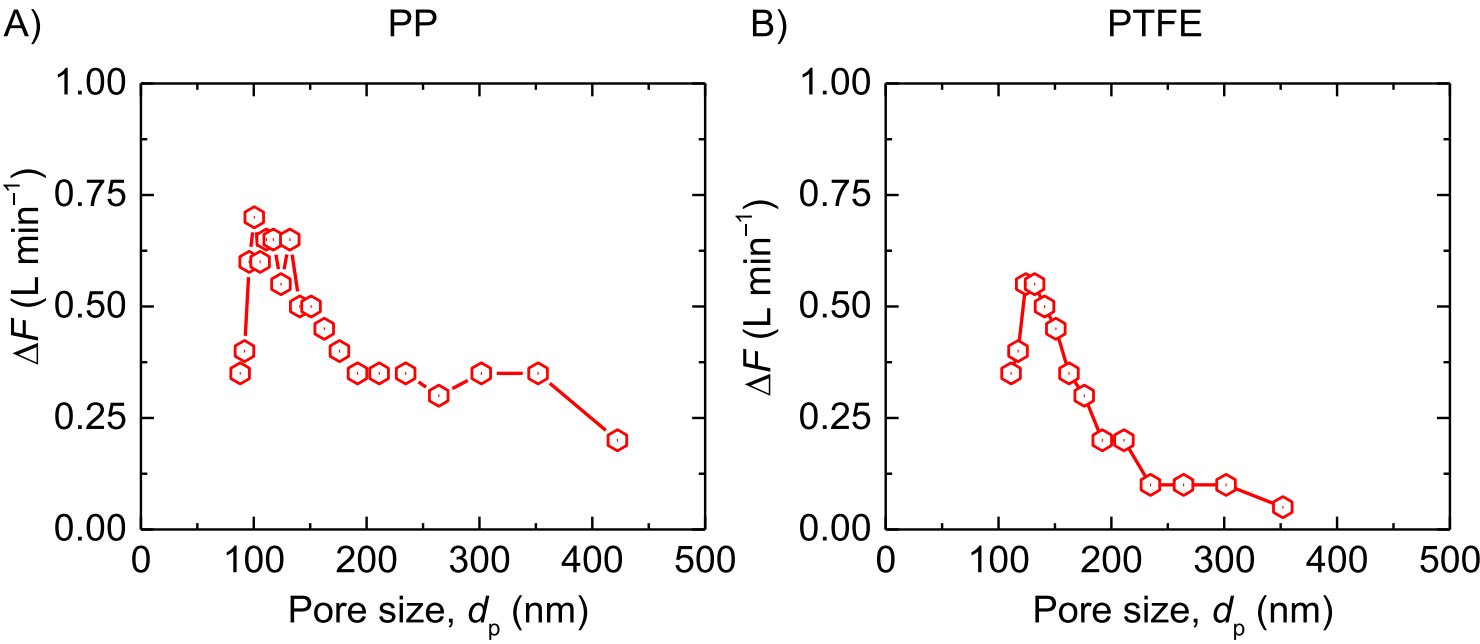

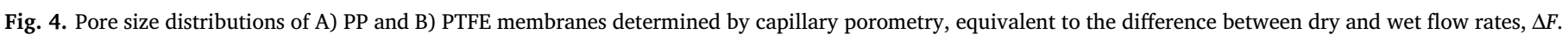


A)

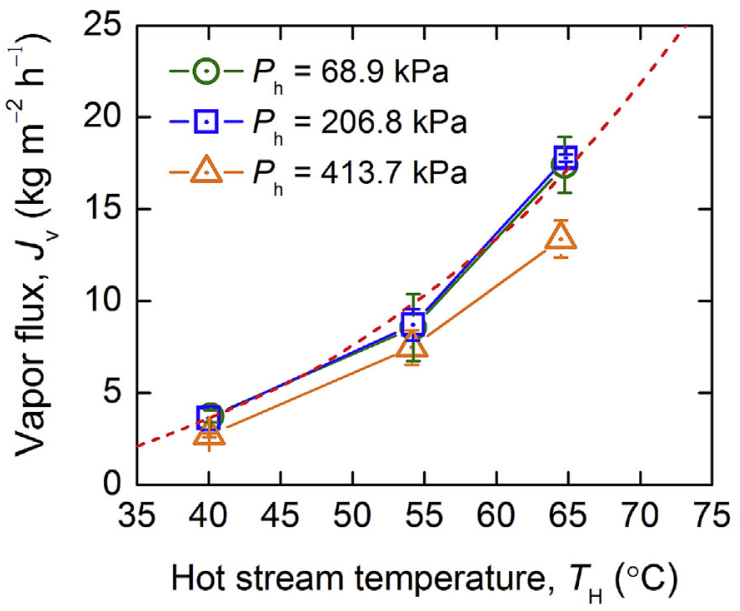

B)

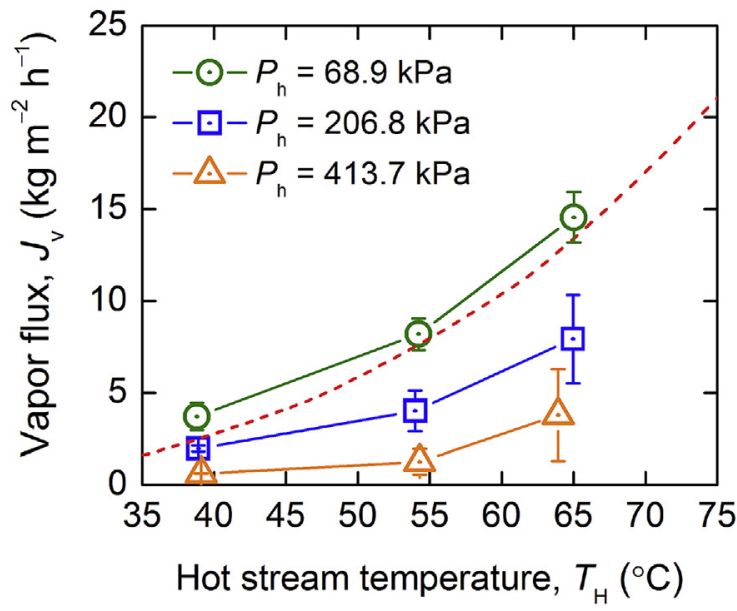

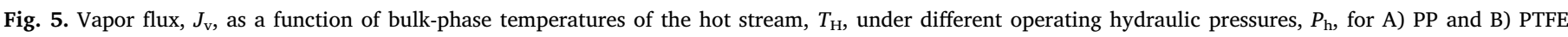

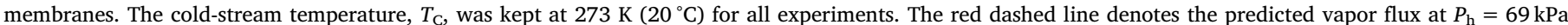

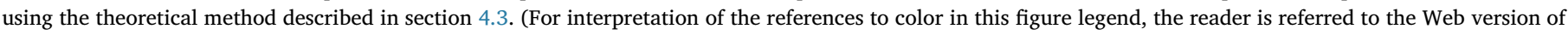
this article.)

using Eqs. (1)-(3). Tortuosity is determined from porosity using the correlation $\tau=\varepsilon^{-1 / 2}[24,46-48]$. Analysis of specific terms in Eq. (1) further reveals the effects of structural parameters $\tau, \delta$, and $\varepsilon$ on VPDO vapor fluxes. The PTFE membrane has a more effective vapor transport pathway than the PP membrane, as represented by the smaller $\tau \delta / \varepsilon$ of $72.4 \mu \mathrm{m}$ compared to $186.7 \mu \mathrm{m}$. Based on Eq. (1), the lower $\tau \delta / \varepsilon$ is more favorable for vapor flux. However, according to Eq. (2), the larger pore size of the PP membrane leads to a much higher Knudsen diffusion coefficient, $0.20 \mathrm{~cm}^{2} / \mathrm{s}$, than that of the PTFE membrane $\left(0.04 \mathrm{~cm}^{2} / \mathrm{s}\right)$. Since molecular diffusion coefficient of both membranes is identical $\left(0.27 \mathrm{~cm}^{2} / \mathrm{s}\right.$, as calculated using Eq. (3)), the observed higher $J_{\mathrm{v}}$ of the PP membrane provides strong evidence that vapor flux through these nanoporous membranes in VPDO is dominated by Knudsen diffusion.

\subsection{Impact of hydraulic pressure on mass transfer}

For the same transmembrane temperature difference, vapor flux in VPDO decreases as the applied hydraulic pressure, $P_{\mathrm{h}}$, is increased. The effect of applied hydraulic pressure on $J_{\mathrm{v}}$ can be explained using the following expression derived from the Kelvin equation:

$P_{\mathrm{v}, \mathrm{C}}=P_{\mathrm{v}, \mathrm{C}}^{*} \exp \left(\frac{P_{\mathrm{h}} V_{\mathrm{m}}}{R_{\mathrm{g}} T_{\mathrm{C}, \mathrm{m}}}\right)$

where $P_{\mathrm{v}, \mathrm{C}}$ is the vapor pressure at the cold stream meniscus, $P_{\mathrm{v}, \mathrm{C}}^{*}$ is the saturated vapor pressure of the cold stream at the liquid-air interface, $T_{\mathrm{C}, \mathrm{m}}$ is the temperature of the cold stream, and $V_{\mathrm{m}}$ is the molar volume of water. Eq. (11) indicates that higher $P_{\mathrm{h}}$ raises vapor pressure of the cold stream meniscus, thereby lowering the transmembrane vapor pressure gradient, $P_{\mathrm{v}, \mathrm{H}}-P_{\mathrm{v}, \mathrm{C}}$, and reducing the driving force for mass transfer.

Vapor fluxes of the PP and PTFE membranes are presented in Fig. 6 as a function of the applied hydraulic pressure, and corresponding predicted vapor fluxes are presented by the dashed lines. Due to the relatively low hydraulic pressures applied in the study, theoretical vapor fluxes only slightly decline as $P_{\mathrm{h}}$ increases, according to the Kelvin equation (Eq. (11)), i.e., the dashed lines have a very small negative slope. As shown in Fig. 6, vapor fluxes of both PP and PTFE membranes are detrimentally affected by the increasing hydraulic pressure, but $J_{\mathrm{v}}$ of the PP membrane are less influenced compared to the PTFE membrane at all transmembrane temperature gradients investigated in this study. We postulate that the applied hydraulic pressure caused compaction of membrane coupons, leading to changes in membrane structural parameters including thickness, porosity, tortuosity, and effective pore size, thereby affecting vapor fluxes. This explains the substantial decrease in experimental $J_{\mathrm{v}}$ compared with the theoretical predictions using constant structural parameters (dashed lines in Fig. 6; details of the model are presented in the following section). Similar results have also been reported in previous VPDO studies $[15,20]$.

The extent of membrane compaction and the resultant impact on vapor flux in VPDO depends on intrinsic membrane properties. Specifically, with a higher porosity (Table 1) and looser structure (Fig. 3), PTFE membrane is more likely to be compacted compared with PP membrane, causing a more significant change in the effective transport pathway, $\tau \delta / \varepsilon$, under pressurization. Meanwhile, because PP membrane has a relatively lower diffusivity dominated by its larger pores, a certain change in $\tau \delta / \varepsilon$ will have less significant impact on its overall vapor permeability coefficient, $B_{\mathrm{v}}$ (Eq. (1)), compared with PTFE membrane. While the two membranes are exposed to the same transmembrane vapor pressure difference under the same pressure, change in $J_{\mathrm{v}}$ of PP membrane due to compaction is less sensitive than PTFE membrane. Compaction of the PP membrane is minimal up to $\approx 210 \mathrm{kPa}$, but becomes noticeable at $\approx 410 \mathrm{kPa}$ (Fig. $6 \mathrm{~A}$ ). On the other hand, vapor flux of the PTFE membrane is already detrimentally affected at the moderate pressure of $\approx 210 \mathrm{kPa}$, suggesting the membrane structure altered significantly due to compaction (Fig. 6B).

\subsection{Impact of membrane chemistry and structure on heat transfer}

Due to temperature polarization, the actual temperature difference across the membrane, $T_{\mathrm{H}, \mathrm{m}}-T_{\mathrm{C}, \mathrm{m}}$, differs from the bulk-phase temperature difference, $T_{\mathrm{H}}-T_{\mathrm{C}}$. The effective driving force for vapor flux is, therefore, reduced by temperature polarization [26,31,32]. At steady state, heat fluxes in the boundary layers of both the hot and cold streams are equal to the heat flux across the membrane, $\dot{Q}$. Temperatures at the liquid-air interface in Eq. (4) are expressed as $T_{\mathrm{H}, \mathrm{m}}=T_{\mathrm{H}}-\dot{Q} / h_{\mathrm{H}}$ and $T_{\mathrm{C}, \mathrm{m}}=T_{\mathrm{C}}+\dot{Q} / h_{\mathrm{C}}$, where $h_{\mathrm{H}}$ and $h_{\mathrm{C}}$ are heat transfer coefficients within the hot- and cold-stream boundary layers, respectively [32]. $h_{\mathrm{H}}$ and $h_{\mathrm{C}}$ are calculated using the Nusselt number, $\mathrm{Nu}$, the boundary layer thermal conductivity, $k_{\mathrm{w}}$, and the hydraulic diameter of the membrane cell channel, $D_{\mathrm{h}}$, using the relation $h=N u$ $\left(k_{\mathrm{w}} / D_{\mathrm{h}}\right)$. Values of $\mathrm{Nu}$ are determined from empirical correlations where flow in the hot-stream channel filled with woven tricot spacer is assumed to be turbulent [31] (denoted by $N u_{\mathrm{H}}^{\mathrm{TF}}$, Eq. (12)) and the 
A)

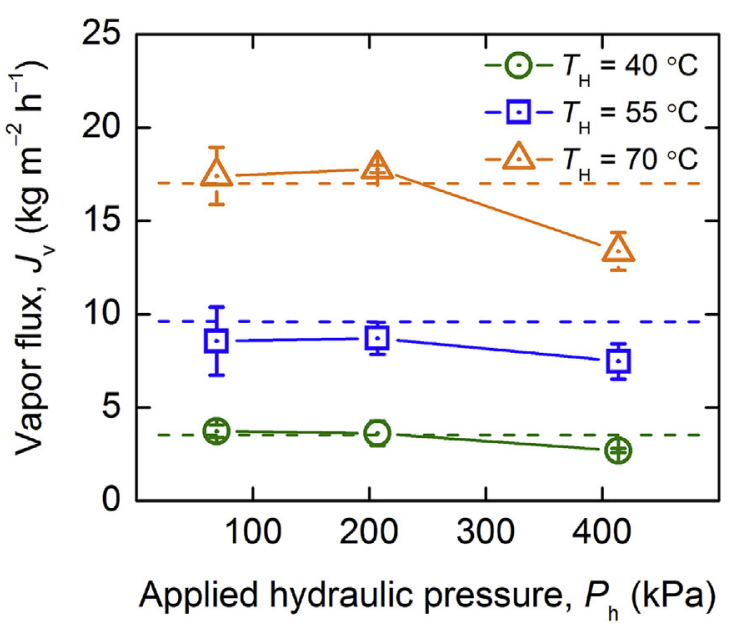

B)

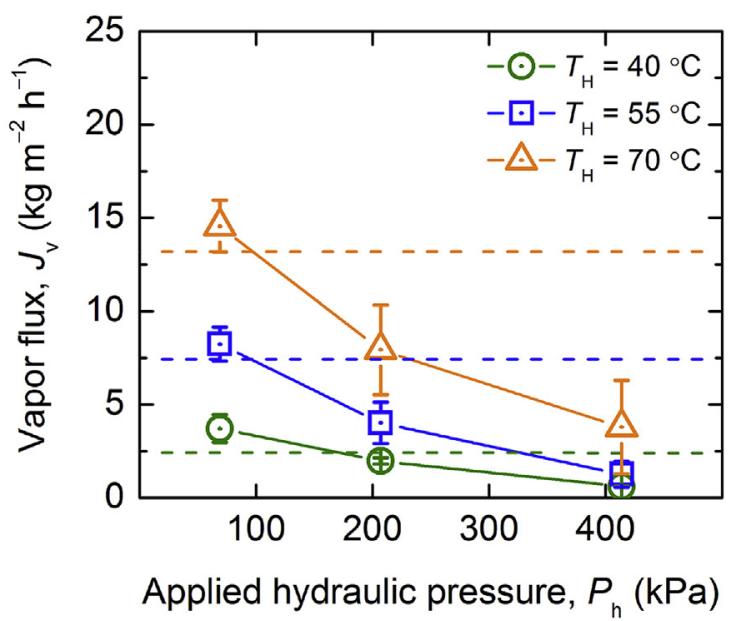

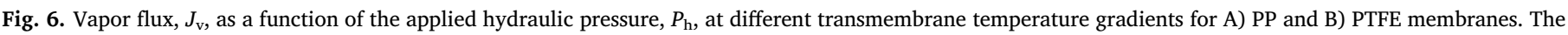

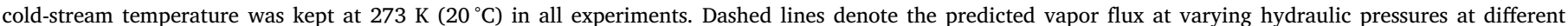
transmembrane temperature difference, assuming constant membrane structural parameters, using the theoretical method described in section 4.3 .

pressurized cold stream is considered to be laminar flow [23,31] (denoted by $N u_{\mathrm{C}}^{\mathrm{LF}}$, Eq. (13)):

$N u_{\mathrm{H}}^{\mathrm{TF}}=0.023\left(1+\frac{6 D_{\mathrm{h}}}{l}\right) \operatorname{Re}^{0.8} P^{1 / 3} r$

$N u_{\mathrm{C}}^{\mathrm{LF}}=4.36+\frac{0.036 \operatorname{Re} \operatorname{Pr}\left(D_{\mathrm{h}} / l\right)}{1+0.0011\left[\operatorname{RePr}\left(D_{\mathrm{h}} / l\right)\right]^{0.8}}$

where $l$ is the length of the channel, $R e$ is the Reynolds number, and $P r$ is the Prandtl number.

Heat flux through the PP and PTFE membranes, $\dot{Q}$, during steadystate VPDO is numerically calculated using Eq. (4) with the experimental $J_{\mathrm{v}}$. Thermal conductivity of the membrane, $k_{\mathrm{m}}$, is determined using the relation, $k_{\mathrm{m}}=(1-\varepsilon) k_{\mathrm{p}}+\varepsilon k_{\mathrm{g}}$, where $k_{\mathrm{p}}$ and $k_{\mathrm{g}}$ are the thermal conductivities of the polymeric membrane material and gas (i.e., air), respectively. The values of $k_{\mathrm{p}}$ were adapted from properties of PP $\left(0.16 \mathrm{~W} \mathrm{~m}^{-1} \mathrm{~K}^{-1}\right)$ and PTFE $\left(0.25 \mathrm{~W} \mathrm{~m}^{-1} \mathrm{~K}^{-1}\right)$ polymer [49], and $k_{\mathrm{g}}$ of $0.022 \mathrm{~W} \mathrm{~m}^{-1} \mathrm{~K}^{-1}$ was taken from the literature [50]. Vapor fluxes of the PP and PTFE membranes at varying temperature gradients and an applied hydraulic pressure of $68.9 \mathrm{kPa}$ calculated using Eqs. (1)-(3) and Eqs. 10 and 11 match the experimental data well (red dashed lines in Fig. 5).

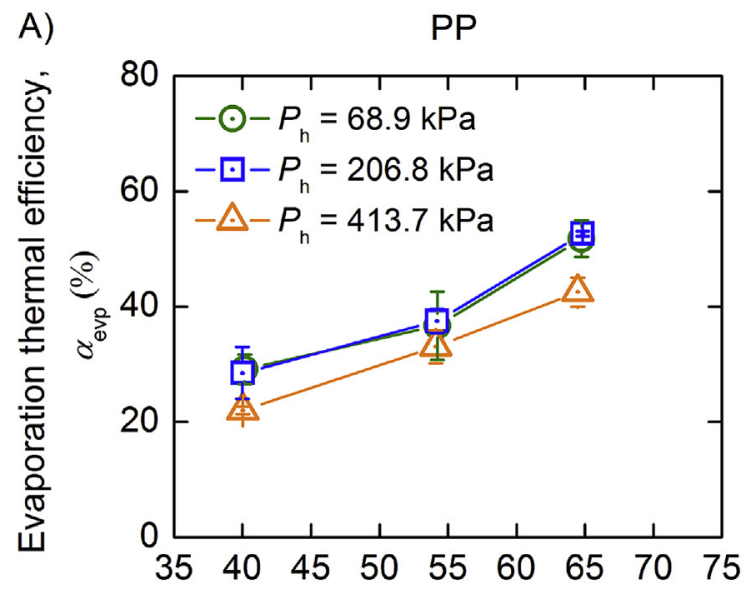

Hot stream temperature, $T_{H}\left({ }^{\circ} \mathrm{C}\right)$
Evaporation thermal efficiencies, $\alpha_{\text {evp }}$, of the PP and PTFE membranes calculated using Eq. (5) are presented in Fig. 7. Evaporation thermal efficiencies of both the PP and PTFE membranes increase with higher temperature gradients across the membrane, but decrease with larger applied hydraulic pressures. We note that the impact of heat transfer associated with vaporization of water $\left(J_{\mathrm{v}} \Delta H_{\mathrm{v}}\right.$ in Eq. (5)) on evaporation thermal efficiency is more significant than conductive heat loss $\left(k_{\mathrm{m}} / \delta\left(T_{\mathrm{H}, \mathrm{m}}-T_{\mathrm{C}, \mathrm{m}}\right)\right.$ in Eq. (5)). This is because $J_{\mathrm{v}}$ and, hence, evaporative heat transfer, is exponentially dependent on the temperature gradient (Clausius-Clapeyron relationship, Eq. (10)), whereas conductive heat transfer is linearly related. Therefore, $\alpha_{\text {evp }}$ exhibits an exponentially increasing tendency with transmembrane temperature difference. The highest $\alpha_{\text {evp }}$ of the PP and PTFE membranes achieved in this study were $51.8 \%$ and $41.7 \%$, respectively, at the same hot-stream temperature, $T_{\mathrm{H}}$, of $70^{\circ} \mathrm{C}$ and applied pressure, $P_{\mathrm{h}}$, of $68.9 \mathrm{kPa}$. Detrimental effects of pressurization on $\alpha_{\text {evp }}$ for both membranes are also observed and, similar to the phenomenon in mass transfer (Figs. 5 and 6), PP is less affected. Again, this is because of the dominance of vaporization of water $\left(J_{\mathrm{v}} \Delta H_{\mathrm{v}}\right)$ in heat transfer, resulting in the performance of $\alpha_{\text {evp }}$ being substantially affected by $J_{\mathrm{v}}$.

In general, the PP membrane presents higher evaporation thermal

B)

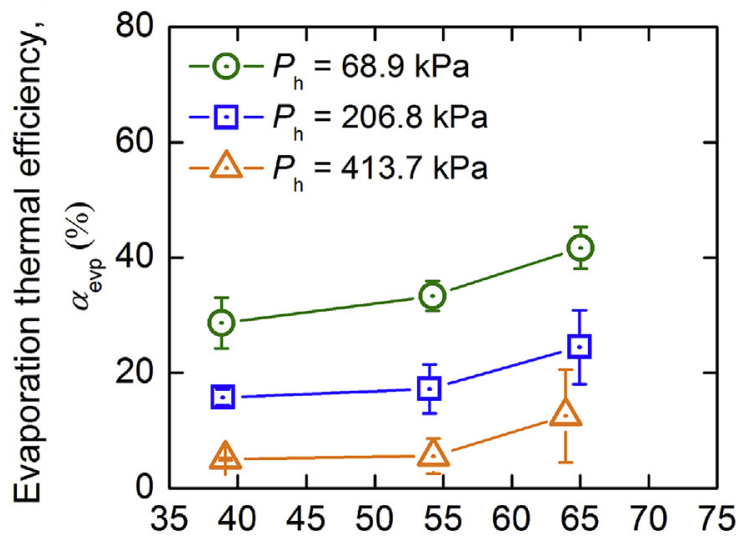

Hot stream temperature, $T_{\mathrm{H}}\left({ }^{\circ} \mathrm{C}\right)$

Fig. 7. Evaporation thermal efficiency, $\alpha_{\text {evp }}$, as a function of hot-stream temperature, $T_{\mathrm{H}}$, under different operating pressures for A) PP and B) PTFE membranes. Coldstream temperature, $T_{\mathrm{C}}$, was set as $273 \mathrm{~K}\left(20^{\circ} \mathrm{C}\right)$. 
efficiency than the PTFE membrane. Since the evaporative heat is carried by vapor flux, membranes with chemical and structural properties more favorable for mass transfer will, consequentially, also tend to have higher $\alpha_{\text {evp. }}$. As discussed in Section 4.2, chemical and structural properties of the PP membrane yield a greater vapor permeability, which explains the higher evaporation thermal efficiency. Similarly, the PP membrane is comparatively less affected under pressurization and exhibited less decay in vapor flux, therefore resulting in smaller decrease in evaporation thermal efficiency under rising hydraulic pressures. Thermal conductivity of the membrane matrix $(0.16$ and $0.22 \mathrm{~W} \mathrm{~m}^{-1} \mathrm{~K}^{-1}$ for PP and PTFE, respectively) does not significantly influence $\alpha_{\text {evp }}$ because of the relatively small contribution of conductive heat loss and the high porosity of the membranes.

\section{Implications of membrane properties for VPDO power generation}

A theoretical model is established to understand mass and heat transfer of the emerging VPDO technology for power generation using low-temperature heat resources. Two commercial hydrophobic nanoporous membranes of different material chemistry, PP and PTFE, and structural properties are evaluated for VPDO performance. Vapor flux and thermal evaporation efficiency of the two membranes demonstrate good agreement with the model predictions. Vapor flux increases exponentially with the transmembrane temperature difference, underscoring the unique attribute of VPDO to advantageously leverage on the exponential dependence of vapor pressure on temperature in the conversion of low-temperature heat sources to useful work.

Thinner membranes with greater porosity and lower tortuosity will yield larger vapor permeabilities, $B_{\mathrm{v}}$ (Fig. 5 and Eq. (1)), that improve vapor flux and, thus, generate better power density performance for VPDO energy production. While membranes with larger pores can facilitate vapor flux by enhancing the dominant transport mechanism of Knudsen diffusion (Eq. (2)), as observed for the PP membranes, performance advancements based on this approach will be constrained by the need to maintain unwetted pores (Eq. (7) and Fig. 4). For superhydrophobic membrane materials, such as PTFE, chemical modifications to lower the surface free energy [51-53], and tailored surface microstructures with special anti-wettability $[54,55]$ can beneficially increase the LEP to enable greater pressurization of the cold stream, and allow membranes with larger pores and higher vapor permeability coefficients to be utilized for VPDO. Composite or asymmetric membranes can decouple the seemingly conflicting structural requirements for anti-wettability and high vapor flux: having small pores at the membrane surface fronting the pressurized stream will resist wetting and allow greater hydraulic pressures to be utilized, and having high porosity and large non-tortuous void structures for the rest of the membranes will facilitate transport for high vapor flux. As the largest pores are the first to be wetted, development of membranes with a narrow dispersion of pore sizes will also be advantageous to enable utilization of higher transmembrane hydraulic pressures.

The study showed that decay in vapor flux because of changes in membrane morphology caused by compaction under hydraulic pressurization is related to membrane structural properties. The desired membrane structure for large $B_{\mathrm{v}}$, i.e., high porosity, appears to be incompatible with resistance to deformation. Therefore, efforts to improve vapor permeability by tuning the membrane structure would also need to balance the mechanical robustness requirement. It is worthwhile to note that the membranes evaluated in this investigation are not designed for the specific operating conditions of VPDO and, hence, there is considerable room for advancement. Here, unique scaffold architectures that are highly porous without sacrificing sturdiness offer opportunities to depart from this apparent tradeoff [56,57].

Evaporation thermal efficiencies improve at higher transmembrane temperature gradients but decrease with larger applied hydraulic pressure, with evaporative heat transfer being considerably more significant than conductive heat loss. While a lower thermal conductivity of the membrane polymer material has been suggested to be beneficial for VPDO [16], its effects on both improving evaporation thermal efficiency and maximizing power generation will be only marginal. Our study indicates that membrane properties desirable for mass transfer, i.e., high vapor permeability and resistance against deleterious compaction, are also key to efficient thermal utilizations of the low-temperature heat resources and, thus, are the primary considerations in developing membrane for high-performance VPDO.

\section{Nomenclature}

\section{Acronyms}

LEP liquid entry pressure

PP polypropylene

PTFE polytetrafluoroethylene

PRMD pressure-retarded membrane distillation

TOEC thermo-osmotic energy conversion

VPDO vapor pressure-driven osmosis

Symbols

$B_{\mathrm{v}} \quad$ membrane vapor permeability $\left(\mathrm{s} \mathrm{m}^{-1}\right)$

$d_{\mathrm{p}} \quad$ pore diameter of the membrane (nm)

$d_{\mathrm{p}, \text { eff }} \quad$ effective mean pore diameter of the membrane (nm)

$d_{\mathrm{p}, \max }$ maximum pore diameter of the membrane (nm)

$D_{\mathrm{h}} \quad$ hydraulic diameter (m)

$D_{\mathrm{K}} \quad$ Knudsen diffusion coefficient $\left(\mathrm{cm}^{2} \mathrm{~s}^{-1}\right)$

$D_{\text {wa }} \quad$ molecular diffusion coefficient of the water-air system $\left(\mathrm{cm}^{2}\right.$ $s^{-1}$ )

$\Delta F \quad$ difference between gas flow rates of the dry and wet membrane $\left(\mathrm{L} \min ^{-1}\right.$ )

$h_{\mathrm{C}} \quad$ heat transfer coefficient of the boundary layer in the cold stream $\left(\mathrm{W} \mathrm{m}{ }^{-2} \mathrm{~K}^{-1}\right)$

$h_{\mathrm{H}} \quad$ heat transfer coefficient of the boundary layer in the hot stream $\left(\mathrm{W} \mathrm{m}{ }^{-2} \mathrm{~K}^{-1}\right)$

$\Delta H_{\mathrm{v}} \quad$ enthalpy of vaporization $\left(\mathrm{kJ} \mathrm{mol}^{-1}\right)$

$J_{\mathrm{v}} \quad$ vapor flux $\left(\mathrm{kg} \mathrm{m}^{-} 2 \mathrm{~h}^{-1}\right)$

$k_{\mathrm{g}} \quad$ thermal conductivity of gas in membrane pores $\left(\mathrm{W} \mathrm{m}^{-1} \mathrm{~K}^{-1}\right)$

$k_{\mathrm{m}} \quad$ integral thermal conductivity of the membrane $\left(\mathrm{W} \mathrm{m}^{-1} \mathrm{~K}^{-1}\right)$

$k_{\mathrm{p}} \quad$ thermal conductivity of the membrane polymer $\left(\mathrm{W} \mathrm{m}^{-1} \mathrm{~K}^{-1}\right)$

$k_{\mathrm{w}} \quad$ thermal conductivity of the boundary layer $\left(\mathrm{mW} \mathrm{m}^{-1} \mathrm{~K}^{-1}\right)$

$l \quad$ length of the water channel (m)

$m_{\text {dry }} \quad$ mass of the dry membrane sample $(\mathrm{g})$

$m_{\text {wet }} \quad$ mass of the wetted membrane sample (g)

$M_{\mathrm{a}} \quad$ molar mass of air molecule $\left(\mathrm{g} \mathrm{mol}^{-1}\right)$

$M_{\mathrm{w}} \quad$ molar mass of water $\left(\mathrm{g} \mathrm{mol}^{-1}\right)$

$p \quad$ bulk pressure in the membrane pore $(\mathrm{kPa})$

$P_{\mathrm{a}} \quad$ pressure of air in the membrane pore $(\mathrm{kPa})$

$P_{\mathrm{h}} \quad$ applied hydraulic pressure $(\mathrm{kPa})$

$P_{\mathrm{v}, \mathrm{C}} \quad$ vapor pressure of the cold stream $(\mathrm{kPa})$

$P_{\mathrm{v}, \mathrm{H}} \quad$ vapor pressure of the hot stream $(\mathrm{kPa})$

$P_{\mathrm{v}, \mathrm{C}}^{*} \quad$ saturated vapor pressure of the reference state at $298 \mathrm{~K}(\mathrm{kPa})$

$\Delta P \quad$ hydraulic pressure difference across the membrane $(\mathrm{kPa})$

$\Delta P_{1, \mathrm{C}} \quad$ pressure difference across the liquid meniscus $(\mathrm{kPa})$

$\dot{Q} \quad$ total heat flux across the membrane $\left(\mathrm{W} \mathrm{m}^{-2}\right)$

$r_{\text {eff }} \quad$ effective pore radius (nm)

$R_{\mathrm{g}} \quad$ gas constant $\left(\mathrm{J} \mathrm{mol}^{-1} \mathrm{~K}^{-1}\right)$

$R_{\text {avg }} \quad$ average surface roughness (nm)

$T$ temperature (K)

$T_{\mathrm{C}} \quad$ bulk phase temperature in the cold stream (K)

$T_{\mathrm{C}}{ }^{*} \quad$ temperature of the reference state $(\mathrm{K})$

$T_{\mathrm{H}} \quad$ bulk phase temperature in the hot stream (K)

$T_{\mathrm{C}, \mathrm{m}} \quad$ membrane interfacial temperature in the cold stream (K)

$T_{\mathrm{H}, \mathrm{m}} \quad$ membrane interfacial temperature in the hot stream (K)

$V_{\mathrm{a}} \quad$ molar volume of air $\left(\mathrm{ml} \mathrm{mol}^{-1}\right)$ 
$V_{\mathrm{m}} \quad$ molar volume of liquid water $\left(\mathrm{ml} \mathrm{mol}^{-1}\right)$

$V_{\mathrm{w}} \quad$ molar volume of water vapor $\left(\mathrm{ml} \mathrm{mol}^{-1}\right)$

\section{Greek letters}

$\alpha_{\text {evp }} \quad$ evaporation thermal efficiency (\%)

$\beta \quad$ constant coefficient for surface free energy $\left(\mathrm{m}^{4} \mathrm{~J}^{-2}\right)$

$\gamma_{1} \quad$ surface tension of liquid $\left(\times 10^{-3} \mathrm{~N} \mathrm{~m}^{-2}\right)$

$\gamma_{\mathrm{s}} \quad$ surface free energy of membrane $\left(\times 10^{-3} \mathrm{~J} \mathrm{~m}^{-2}\right)$

$\delta_{\mathrm{m}} \quad$ membrane thickness $(\mu \mathrm{m})$

$\delta_{\text {spt }} \quad$ thickness of membrane support $(\mu \mathrm{m})$

$\varepsilon \quad$ membrane porosity (\%)

$\theta_{\text {app }}$ apparent water contact angle on a rough membrane surface ${ }^{\circ}$ )

$\theta_{\text {in }} \quad$ intrinsic water contact angle on a smooth surface $\left({ }^{\circ}\right)$

$\rho_{\mathrm{p}} \quad$ density of the membrane polymer $\left(\mathrm{g} \mathrm{cm}^{-3}\right)$

$\rho_{\mathrm{w}} \quad$ density of water $\left(\mathrm{g} \mathrm{cm}^{-3}\right)$

$\tau \quad$ pore tortuosity

Dimensionless groups

$\mathrm{Nu} u_{\mathrm{C}}^{\mathrm{LF}} \quad$ Nusselt number for laminar flow in the cold stream

$N u_{\mathrm{H}}^{\mathrm{TF}} \quad$ Nusselt number for turbulent flow in the hot stream

$\mathrm{Pr} \quad$ Prandtl number

$r_{\mathrm{rg}} \quad$ roughness factor

Re Reynolds number

Superscripts and subscripts

\section{a air}

app apparent

avg average

C cold stream side

d diameter

gas

$H \quad$ hot stream side

$h \quad$ hydraulic

in intrinsic

int integral

$K \quad$ Knudsen diffusion

$l \quad$ liquid

LF laminar flow

$m \quad$ membrane/membrane interfacial

$\max \quad$ maximum

polymer

rg rough

$s \quad$ solid

spt membrane support

TF turbulent flow

w water

* $\quad$ reference condition

\section{References}

[1] I. Johnson, W.T. Choate, A. Davidson, Waste Heat Recovery: Technology and Opportunities in US Industry, BCS, Inc., Laurel, MD (United States), 2008.

[2] C. Forman, I.K. Muritala, R. Pardemann, B. Meyer, Estimating the global waste heat potential, Renew. Sustain. Energy Rev. 57 (2016) 1568-1579.

[3] T. Hendricks, W.T. Choate, Engineering Scoping Study of Thermoelectric Generator Systems for Industrial Waste Heat Recovery, Pacific Northwest National Lab. (PNNL), Richland, WA (United States), 2006.

[4] Annual Energy Outlook 2019, U.S. Energy Information Administration, 2019, www. eia.gov/aeo.

[5] D. Blackwell, M. Richards, Z. Frone, A. Ruzo, R. Dingwall, M.J.G.T. Williams, Temperature-at-depth maps for the conterminous US and geothermal resource estimat, GRC Trans. 35 (2011).

[6] J.W. Tester, B.J. Anderson, A. Batchelor, D. Blackwell, R. DiPippo, E. Drake, J. Garnish, B. Livesay, M. Moore, K. Nichols, The future of geothermal energy, Impact of Enhanced Geothermal Systems on the United States in the 21st Century, 2006, p. 372.

[7] L.E. Bell, Cooling, heating, generating power, and recovering waste heat with thermoelectric systems, Science 321 (2008) 1457-1461.

[8] M. Zebarjadi, K. Esfarjani, M. Dresselhaus, Z. Ren, G. Chen, Perspectives on thermoelectrics: from fundamentals to device applications, Energy Environ. Sci. 5 (2012) 5147-5162

[9] P. Peljo, D. Lloyd, N. Doan, M. Majaneva, K. Kontturi, Towards a thermally regenerative all-copper redox flow battery, Phys. Chem. Chem. Phys. 16 (2014) 2831-2835.

[10] F. Zhang, N. LaBarge, W. Yang, J. Liu, B.E. Logan, Enhancing low-grade thermal energy recovery in a thermally regenerative ammonia battery using elevated temperatures, ChemSusChem 8 (2015) 1043-1048.

[11] F. Zhang, J. Liu, W. Yang, B.E. Logan, A thermally regenerative ammonia-based battery for efficient harvesting of low-grade thermal energy as electrical power, Energy Environ. Sci. 8 (2015) 343-349.

[12] T.J. Abraham, D.R. MacFarlane, J.M. Pringle, High Seebeck coefficient redox ionic liquid electrolytes for thermal energy harvesting, Energy Environ. Sci. 6 (2013) 2639-2645.

[13] R. Hu, B.A. Cola, N. Haram, J.N. Barisci, S. Lee, S. Stoughton, G. Wallace, C. Too, M. Thomas, A. Gestos, Harvesting waste thermal energy using a carbon-nanotubebased thermo-electrochemical cell, Nano Lett. 10 (2010) 838-846.

[14] S.W. Lee, Y. Yang, H.-W. Lee, H. Ghasemi, D. Kraemer, G. Chen, Y. Cui, An electrochemical system for efficiently harvesting low-grade heat energy, Nat. Commun. 5 (2014) 3942.

[15] A.P. Straub, N.Y. Yip, S. Lin, J. Lee, M. Elimelech, Harvesting low-grade heat energy using thermo-osmotic vapour transport through nanoporous membranes, Nat. Energy 1 (2016) 16090.

[16] A.P. Straub, M. Elimelech, Energy efficiency and performance limiting effects in thermo-osmotic energy conversion from low-grade heat, Environ. Sci. Technol. 51 (2017) 12925-12937.

[17] M. Rahimi, A.P. Straub, F. Zhang, X. Zhu, M. Elimelech, C.A. Gorski, B.E. Logan, Emerging electrochemical and membrane-based systems to convert low-grade heat to electricity, Energy Environ. Sci. 11 (2018) 276-285.

[18] K. Park, D.Y. Kim, D.R. Yang, Theoretical analysis of pressure retarded membrane distillation (PRMD) process for simultaneous production of water and electricity, Ind. Eng. Chem. Res. 56 (2017) 14888-14901.

[19] E. Shaulsky, V. Karanikola, A.P. Straub, A. Deshmukh, I. Zucker, M. Elimelech, Asymmetric membranes for membrane distillation and thermo-osmotic energy conversion, Desalination 452 (2019) 141-148.

[20] Z. Yuan, L. Wei, J.D. Afroze, K. Goh, Y. Chen, Y. Yu, Q. She, Y. Chen, Pressureretarded membrane distillation for low-grade heat recovery: the critical roles of pressure-induced membrane deformation, J. Membr. Sci. 579 (2019) 90-101.

[21] R. Krishna, J. Wesselingh, The Maxwell-Stefan approach to mass transfer, Chem. Eng. Sci. 52 (1997) 861-911.

[22] E.A. Mason, A. Malinauskas, Gas Transport in Porous Media: the Dusty-Gas Model, Elsevier Science Ltd, 1983.

[23] M. Gryta, M. Tomaszewska, Heat transport in the membrane distillation process, J. Membr. Sci. 144 (1998) 211-222.

[24] A. Deshmukh, M. Elimelech, Understanding the impact of membrane properties and transport phenomena on the energetic performance of membrane distillation desalination, J. Membr. Sci. 539 (2017) 458-474.

[25] J. Lee, A.P. Straub, M. Elimelech, Vapor-gap membranes for highly selective osmotically driven desalination, J. Membr. Sci. 555 (2018) 407-417.

[26] K.W. Lawson, D.R. Lloyd, Membrane distillation, J. Membr. Sci. 124 (1997) 1-25.

[27] M. Khayet, Membranes and theoretical modeling of membrane distillation: a review, Adv. Colloid Interface Sci. 164 (2011) 56-88.

[28] W. Kast, C.-R. Hohenthanner, Mass transfer within the gas-phase of porous media, Int. J. Heat Mass Transf. 43 (2000) 807-823.

[29] M.M. Clark, Transport Modeling for Environmental Engineers and Scientists, second ed., John Wiley \& Sons, 2011.

[30] D.W. Green, R.H. Perry, Perry's Chemical Engineers' Handbook, eighth ed., McGraw-Hill Education, 2007.

[31] J. Phattaranawik, R. Jiraratananon, A. Fane, Heat transport and membrane distillation coefficients in direct contact membrane distillation, J. Membr. Sci. 212 (2003) 177-193.

[32] M. Qtaishat, T. Matsuura, B. Kruczek, M. Khayet, Heat and mass transfer analysis in direct contact membrane distillation, Desalination 219 (2008) 272-292.

[33] A.W. Adamson, A.P. Gast, Physical Chemistry of Surfaces, sixth ed., (1997).

[34] D.Y. Kwok, A.W. Neumann, Contact angle measurement and contact angle interpretation, Adv. Colloid Interface Sci. 81 (1999) 167-249.

[35] R.N. Wenzel, Resistance of solid surfaces to wetting by water, Ind. Eng. Chem. 28 (1936) 988-994.

[36] K. Smolders, A. Franken, Terminology for membrane distillation, Desalination 72 (1989) 249-262.

[37] S. Nejati, C. Boo, C.O. Osuji, M. Elimelech, Engineering flat sheet microporous PVDF films for membrane distillation, J. Membr. Sci. 492 (2015) 355-363.

[38] M. Khayet, T. Matsuura, Preparation and characterization of polyvinylidene fluoride membranes for membrane distillation, Ind. Eng. Chem. Res. 40 (2001) 5710-5718.

[39] M.K. Souhaimi, T. Matsuura, Membrane Distillation: Principles and Applications, Elsevier, 2011.

[40] D.R. Lloyd, K.E. Kinzer, H. Tseng, Microporous membrane formation via thermally induced phase separation. I. Solid-liquid phase separation, J. Membr. Sci. 52 (1990) 239-261.

[41] M. Gryta, Influence of polypropylene membrane surface porosity on the performance of membrane distillation process, J. Membr. Sci. 287 (2007) 67-78.

[42] M. Khayet, K. Khulbe, T. Matsuura, Characterization of membranes for membrane distillation by atomic force microscopy and estimation of their water vapor transfer coefficients in vacuum membrane distillation process, J. Membr. Sci. 238 (2004) $199-211$. 
[43] D.K. Owens, R. Wendt, Estimation of the surface free energy of polymers, J. Appl. Polym. Sci. 13 (1969) 1741-1747.

[44] J. Miller, S. Veeramasuneni, J. Drelich, M. Yalamanchili, G. Yamauchi, Effect of roughness as determined by atomic force microscopy on the wetting properties of PTFE thin films, Polym. Eng. Sci. 36 (1996) 1849-1855.

[45] M. Khayet, A. Velázquez, J.I. Mengual, Modelling mass transport through a porous partition: effect of pore size distribution, J. Non-Equil.Thermody. 29 (2004) 279-299.

[46] V.D. Bruggeman, Berechnung verschiedener physikalischer Konstanten von heterogenen Substanzen. I. Dielektrizitätskonstanten und Leitfähigkeiten der Mischkörper aus isotropen Substanzen, Ann. Phys. 416 (1935) 636-664.

[47] A. Berson, H.W. Choi, J.G. Pharoah, Determination of the effective gas dif- fusivity of a porous composite medium from the three-dimensional reconstruction of its microstructure, Phys. Rev. E 83 (2011) 026310.

[48] L. Shen, Z. Chen, Critical review of the impact of tortuosity on diffusion, Chem. Eng. Sci. 62 (2007) 3748-3755.

[49] D.W. Van Krevelen, K. Te Nijenhuis, Properties of Polymers: Their Correlation with Chemical Structure; Their Numerical Estimation and Prediction from Additive Group Contributions, Elsevier, 2009.

[50] C.L. Yaws, Handbook of Transport Property Data, Viscosity, Thermal Conductivity, and Diffusion Coefficients of Liquids and Gases, Library of physico-chemical property data, Gulf Publishing, Houston, 1995.

[51] Z.-Q. Dong, X.-h. Ma, Z.-L. Xu, W.-T. You, F.-b. Li, Superhydrophobic PVDF-PTFE electrospun nanofibrous membranes for desalination by vacuum membrane distillation, Desalination 347 (2014) 175-183.

[52] B.S. Lalia, E. Guillen-Burrieza, H.A. Arafat, R. Hashaikeh, Fabrication and characterization of polyvinylidenefluoride-co-hexafluoropropylene (PVDF-HFP) electrospun membranes for direct contact membrane distillation, J. Membr. Sci. 428 (2013) 104-115.

[53] C. Yang, X.-M. Li, J. Gilron, D.-f. Kong, Y. Yin, Y. Oren, C. Linder, T. He, CF4 plasma-modified superhydrophobic PVDF membranes for direct contact membrane distillation, J. Membr. Sci. 456 (2014) 155-161.

[54] E.-J. Lee, A.K. An, P. Hadi, S. Lee, Y.C. Woo, H.K. Shon, Advanced multi-nozzle electrospun functionalized titanium dioxide/polyvinylidene fluoride-co-hexafluoropropylene (TiO2/PVDF-HFP) composite membranes for direct contact membrane distillation, J. Membr. Sci. 524 (2017) 712-720.

[55] Y. Liao, R. Wang, A.G. Fane, Fabrication of bioinspired composite nanofiber membranes with robust superhydrophobicity for direct contact membrane distillation, Environ. Sci. Technol. 48 (2014) 6335-6341.

[56] Q. She, J. Wei, N. Ma, V. Sim, A.G. Fane, R. Wang, C.Y. Tang, Fabrication and characterization of fabric-reinforced pressure retarded osmosis membranes for osmotic power harvesting, J. Membr. Sci. 504 (2016) 75-88.

[57] L.A. Hoover, J.D. Schiffman, M. Elimelech, Nanofibers in thin-film composite membrane support layers: enabling expanded application of forward and pressure retarded osmosis, Desalination 308 (2013) 73-81. 